\title{
Systems Thinking for Managing COVID-19 in Health Care Systems: Seven Key Messages
}

\author{
Phillips, Janet M; Stalter, Ann M.
}

\begin{abstract}
This article provides the most current guidelines for nurse educators and nurses to use systems thinking to manage COVID-19 in health systems. A working definition of systems thinking is offered, with a review of basic knowledge and care in the context of the system awareness model (SAM). Seven key messages assist nurse educators and nurses in the management of COVID-19 patients culminating in leadership of complex health care systems using systems thinking.
\end{abstract}

Keywords: infections, vaccines, nursing education, COVID-19

There is a new reality for today's health care providers, given the unprecedented spread and devastation of the global pandemic caused by the novel coronavirus. This situation represents the gravest health challenge that the world has faced in over a century, with the unpredictability of events challenging an already stressed health care system. At the time this article was written, information is changing rapidly, particularly in managing the spread of COVID-19 (otherwise known as Coronavirus Disease-2019). Up-to-date information can be found on the websites for the Center for Disease Control and Prevention (CDC, 2020) and the World Health Organization (WHO, 2020a). Needless to say, there is a lack of literature about the management of COVID-19 using systems thinking in health care settings.

On December 31, 2019, WHO was informed of cases of pneumonia with unknown etiology from Wuhan City, Hubei Province of China (WHO, 2020a). An outbreak of a novel type of coronavirus was reported with exposures apparently from one live animal market in Wuhan City. It quickly spread to the neighboring countries within days, and in several months to follow, it had spread to nearly every country in the world, leading to the deaths of hundreds of thousands of people worldwide. The outbreak was declared a Public Health Emergency of International Concern on January 30, 2020, by WHO (2020). On February 11, 2020, WHO announced a name for the new coronavirus disease, COVID-19. By March 11, 2020, it was officially declared a pandemic by WHO (WHO, 2020a).

This article provides the most current guidelines for nurse educators and nurses who manage COVID-19 in health systems using systems thinking. A working definition of systems thinking is offered, with a review of basic knowledge and care in the context of the system awareness model (SAM) (Phillips et al., 2016). Seven key messages assist nurse educators and nurses in the management of COVID-19 patients' care in complex health care systems using systems thinking.

\section{Systems Thinking Definition}

This is the author's manuscript of the article published in final edited form as: 
Systems thinking is defined as "a process applied to individuals, teams, and organizations to impact cause and effect where solutions to complex problems are accomplished through collaborative effort according to personal ability with respect to improving components and the greater whole" (Stalter et al., 2016, p. 323). Systems thinking can be regarded as a way of viewing, communicating, and understanding relationships that determine the functioning of systems (Smith et al., 2017). It is a process that connects the etiology of system-based problems to adverse consequences with improvement processes and outcomes (Notarnicola et al., 2019). An author-created model, the SAM (Phillips et al., 2016; Phillips et al., 2019) can be used by health care professionals as they navigate the challenges of the COVID-19 pandemic in health systems. Utilizing the SAM develops awareness of systems thinking, culminating in confidence and leadership in complex health systems.

\section{The SAM: Introduction and Use}

The SAM has been used to advance patient quality and safety within academic and health systems (Phillips et al., 2018; Stalter et al., 2019). Originally designed to address systems thinking in RN-to-BSN curricula (Phillips et al., 2016), the SAM model is used to address the multiple systems that influence a current problem, placing it in context and showing sensitivity to how the problem evolved and where the solution to the problem might lead.

The SAM is presented as a pyramid structure incorporating seven successive steps. Beginning at step 1, nurses advance upward, progressively increasing system-level awareness. Starting out, nurses demonstrate high personal effort and reliance on authority. Along the way, nurses become systemsthinkers, integrating experience, competency, and ethics to build leadership capacity. By the time nurses reach step 7 , they demonstrate high critical reasoning and an increased awareness of interdependencies with vital members of the health care team. The pinnacle of systems thinking is the ability to lead complex health care systems while demonstrating confidence, compassion, and empathy for oneself, patients, patients' families, and peers.

The SAM (Phillips et al., 2016) has been modified for use in descriptive studies and has been recommended for improving quality and safety within both academic and practice systems (Phillips et al., 2018; Stalter \& Jauch, 2019). Use of the SAM reinforces quality and safety through stepwise progression. Each step is aligned with Dolansky's and Moore's (2013) Systems Thinking Scale, which allows for systems thinking measurement among interprofessional teams working within complex health care systems. For the purposes of this article, the SAM has been modified for managing COVID-19 in current U.S. health systems (Figure 1).

\section{Modified SAM for Managing COVID-19 Patients}

The modified SAM for managing COVID-19 in health systems begins with acquiring basic knowledge for the care of COVID-19 patients. The process initiates with individual awareness of the coronavirus itself, how the human body responds to it across the lifespan, and the nursing care and management of COVID-19 patients. Nurses focus on infection control while progressing through the seven steps and taking personal responsibility for confidently leading others toward quality and safety in complex health 
care systems. The SAM adaptation for managing COVID-19 patients in health systems is presented in Table 1.

\section{Seven Key Messages for Managing COVID-19 in Health Systems \\ Message 1: Basic Nursing Knowledge and Care of COVID-19 Patients}

The focus of message 1 is basic nursing knowledge and care of COVID-19 patients in health care settings. Given the extensive publicity offered for prevention, nurses are aware that COVID-19 is a potentially fatal disease of great concern to public health within their health care system (Rothan \& Byrareddy, 2020) until a vaccine is available. In review of current evidence, the majority of fatal confirmed cases are older adults (over 60 years of age) with comorbidities (such as diabetes, cardiovascular disease, chronic lung disease) (CDC, 2020). However, recent reports worldwide have revealed a significant increase in the incidence of people under age 50, including children and infants, who have tested positive for COVID-19 (WHO, 2020a), adding to prevalence, morbidity, and mortality rates. Patients initially present with flulike mild respiratory symptoms, such as rhinorrhea, sneezing, sore throat, and possibly loss of taste and smell (CDC, 2020). Systemic disorders can ensue with fever, cough, fatigue, and hypoxemia, and eventually the coronavirus targets the lower airway and high levels of cytokines (cytokine storm), pneumonia, and intestinal symptoms such as diarrhea may occur (Bassetti et al., 2020; Zarracina \& Rodriguez, 2020). It is hypothesized that the cytokine storm influences mortality rates (Channappanavar \& Perlman, 2017).

Health care professionals must know that coronavirus is highly contagious, with a rapidly spreading global effect (WHO, 2020a). The case fatality ratio has been calculated to be $2.2 \%$ (Bassetti et al., 2020); however, it is difficult to accurately measure given that unconfirmed cases may not be reported worldwide (Battegay et al., 2020). The median time from the onset of COVID-19 symptoms to death is 14 days, although this is dependent upon age, the presence of comorbidities, and the status of the patients' immune status (CDC, 2020). The coronavirus incubation period is 5.2 days (Bassetti et al., 2020). Although this information is still evolving, it is believed that the infection can persist for 25 days (CDC, 2020).

Knowledge of the modes of transmission from human-to-human and its spread to the greater community is imperative as triage takes place to identify patients who need hospitalized care (CDC, 2020). The viral load of the coronavirus has been found to be high in both symptomatic and asymptomatic patients, suggesting that transmission may occur before symptoms are apparent (Zou et al., 2020). The viral load of the coronavirus influences the intensity of cytokine response and recovery. Transmission of the coronavirus between humans is believed to occur through direct contact between individuals, coughing and sneezing (airborne), direct exposure to body substances, and contamination of surfaces (CDC, 2020). Health care professionals must understand the basics of the immunology of coronavirus, how it spreads, and how to protect themselves from becoming infected.

People with mild symptoms are encouraged to self-isolate for at least 14 days unless they become very sick and need immediate medical attention. According to the WHO (2020), self-initiated isolation by people with mild symptoms is the most important community intervention to reduce virus transmission 
and, consequently, the burden on health care systems. Currently, there is promise showing effective pharmaceutical anti-viral treatments for managing COVID-19 patients by decreasing the length of the illness (Stanford Medicine, 2020). Meanwhile, scientists around the globe are working together to develop, test, and conduct clinical trials for a vaccine to prevent COVID-19 (WHO, 2020a). However, there is a possibility that the COVID-19 virus may mutate over time, requiring seasonal immunizations (WebMD, 2020).

According to the CDC (2020), it is important for health care workers to encourage people who are infected with coronavirus and have mild symptoms to stay at home and self-isolate rather than seeking testing and/or medical attention for unnecessary testing and hospitalizations. Self-quarantine saves precious medical resources for the very sick and helps to prevent the spread of infection to others. Hand washing (for at least 20 seconds) and/or using alcohol-based hand sanitizer (a minimum of 60\% isopropyl alcohol) for hand hygiene, coughing into one's elbow or a tissue, not touching one's face, and social distancing (at least 6 feet) are important and effective ways to slow the spread of coronavirus in health care systems and in the community (CDC, 2020).

\section{Message 2: System-Based Awareness of Managing Infected Patients}

The focus of message 2 is systems-based awareness for managing COVID-19 (confirmed coronavirus) cases. The health care delivery in the United States is a dynamic, complex, interconnected, and living system. As chaotic as it is, the system is an open one, with inputs, throughputs, outputs, and feedback mechanisms - that is, people can move in and out of the system as needed to both give and receive care. No matter what type of health care setting, nurses and patients are at the core of the pandemic. Nursing is critical to the heart of the health care system. At this time, isolation precautions with protective equipment within the U.S. health care system is mandated to follow CDC recommendations, beginning with testing to rule out cases. Given this, the CDC updates its website every 24 hours, routinely at 4:00 p.m. Eastern Standard Time. Their website is the most credible place for health care providers to refer to in order to implement the most current evidence-informed guidelines in clinical practice settings. In addition, each health care facility should be following an Incident Command System (ICS), which assigns point contacts (key persons) to inform downstream personnel with up-to-date changes such as initiating new protocols (Veenema, 2020). Nurses should identify who the agency ICS point of contact is and how communication flows to the patient care team.

Currently, isolation precautions with protective equipment (PPE) for individuals coming in contact with COVID-19 patients include adhering to standard and transmission-based precautions. This means that in addition to hand washing and using gloves, eye protection, isolation gowns, face masks, and N95 respirators are required (CDC, 2020). Guidelines pertaining to equipment and its use may change as public health data and medical studies are shared with government agencies (WHO, 2020a).

Systems-based awareness provides a gateway for appreciating the value of sharing information for best management of COVID-19 patients. Open systems have a constant flow of information up, down, and across. Nurses must know their direct line of communication (i.e., "up" line is to whom one answers, and the "down" line is to whom one delegates). Nurses must also recognize which parts of their health care system will be affected by the information obtained and by the actions of individual nurses and of 
health care teams. This refers to the flow of information across the system. In crisis situations, it is imperative to recognize the rippling effect of information on health care systems, particularly that unitlevel decisions affect the greater whole (Marcus et al., 2015).

Nurses can link the interconnecting components of systems by providing quality and safety actions with team members to protect patients from harm. In systems language, this linkage is referred to as creating synergy. Translating synergy to the chaotic U.S. health care system during the coronavirus pandemic involves establishing social order that preserves health care system functions while protecting the public's good. In addition, it requires adherence to the CDC-recommended standard and transmissionbased precautions of proper hand washing and use of gloves, eye protection, isolation gowns, face masks, and $\mathrm{N} 95$ respirators (CDC, 2020).

\section{Message 3: Critical Reasoning of Today's Health Care Challenges-Weighing the Risks Between Caring for Patients and Becoming Infected}

On the path toward leadership in systems awareness, message 3 involves critical reasoning of today's health care challenges, such as weighing the risks associated with managing the spread of the coronavirus, and/or becoming infected, while caring for COVID-19 patients. Although top-down decisions made in health care organizations weigh the risks for nurses caring for COVID-19 patients, in an ideal world all nurses and nurse leaders need to be "at the table" to advocate for weighing and making decisions which can put nurses at risk. Systems thinking offers a means to address what is best for the greater good, while caring for COVID-19 patients.

Weighing the risks associated with the coronavirus within complex health care systems involves a matrix of interactions, such as establishing guidelines to protect both health care providers' and the public's health (McLean, 2012). For example, in terms of system inputs, a solution to triaging those who have mild symptoms (e.g., fever, coughing, and dyspnea) has been used in drive-by testing centers and telehealth options that divert entry of patients into primary care offices, urgent care clinics, and emergency departments. In addition, patients with symptoms self-sequester by sheltering in place.

At this point in time, most U.S. citizens know not to seek care at hospitals until they show extreme symptoms of dyspnea. These diversions exemplify that routine medical care is different today than before President Trump declared the United States as being in a state of emergency (Whitehouse.gov, 2020). The partnership between business leaders and the public health authorities has established a new baseline for addressing how health care providers manage active cases entering the health care system. The actions of state and federal agencies will influence how health care professionals critically reason and respond to the challenges of managing the spread of the coronavirus while caring for COVID19 patients.

In terms of system throughputs, weighing the risks of care provision of those affected by the coronavirus, health care professionals are in a new phase of care rendering. The phase is described by disaster experts as Crisis Care Decision-making (CCD) (Hick et al., 2020). When using CCD, prioritization starts with determining provider health risk and ends with answering the hard question, is intervention to this patient worth risking the spread of the disease? According to Hick et al. (2020), Crisis Standards 
of Care are implemented using scoring tools for ventilator and dialysis triaging, as well as by closing customary care options such as urgent care clinics and surgery services.

Restricting customary care options is designed to accommodate what is described by Barbera et al. (2007) as managing "surge capacity" (p. l-3). Surge capacity is used to ensure that the health system can provide the service for society that is intended. From a system perspective, if throughput operations are overburdened, a lack of equipment and supplies place workers at risk for not being able to provide safe care or make ethical decisions (McLean, 2012). An example of weighing such risks is seen when health care organizations choose to limit supplies and/or equipment.

How nurses weigh risk under crisis care standards does not supersede the provision of safe, quality care. McLean (2012) stated that equipment restrictions "are ethically justifiable only when failure to implement [safety protocols] result in grave harm to the functioning of society or to public well-being" (Part IV, para 4.). System outputs are signified by public health epidemiologic data representing not only a flattened prevalence curve, but more so by recovery and resource data. Such data infer not only a riskto-benefit balance but a functioning health care system. Feedback occurs because of upline decisions that are made based on system output data.

\section{Message 4: Quality and Safety Education for Nurses Mastery Within Overwhelmed Health Systems}

Message 4 reinforces patient quality and safety competency as a foundation for improving the chaotic U.S. health care system by preventing patient harm. Prior to the pandemic, the third leading cause of death in the United States was related to medical errors caused by health system breakdowns (Makary \& Daniel, 2016). As many of the U.S. health care systems are rapidly becoming overburdened from the influx of COVID-19 patients, the essential Quality and Safety Education for Nurses (QSEN) competencies of collaborating with professionals to provide safe, quality, patient-centered care using the best available evidence and technology that yields effective health outcomes cannot waver (QSEN, 2020). To reduce system burden, upon entry into the health care system, advanced directives should be assessed and obtained. Next, an assessment on coronavirus severity and risk factors is important for determining a level of resource exigency. Finally, crucial conversations about realistic interventions given the availability of supplies and financial resources is paramount.

Health care professionals must apply evidence-based strategies to address ethical decisions. For example, Catalano's (1997) ethical algorithm can provide a five-step decision-making process to help nurses and patients to resolve difficult choices. First, the nurse collects, analyzes, and interprets data provided by the patient and/or their family. Second, the nurse states the dilemma to the patient and/or their family out loud using words that they have used. Third, the nurse provides possible choices of action, sharing them with the patient and/or their family. Fourth, the nurse helps the patient and/or their family consider the advantages and disadvantages of the possible choices. Finally, a decision is made. Airth-Kindree and Kirkhorn (2016) recommended that health care team members explore possible solutions to ethical dilemmas by use of ethical grand rounds. Such discussions ensure that all people involved in the decision have resolution. 


\section{Message 5: System-Level Analysis Based on Professional Standards of Conduct: WHO, CDC, State, Joint Commission, and Universities and Schools of Nursing}

Message 5 addresses system-level analyses that are based on international standards and serve as references that should be used as a resource in the United States during this pandemic. For example, analysis of system factors can be based on professional standards of conduct as guided by the WHO, CDC, state departments of health, Joint Commission, and policies for students at universities and schools of nursing who interact with health care systems. Nurses on the front lines are challenged to adhere to professional standards of conduct as set forth by such governing agencies and credentialing bodies. The CDC-updated Guiding Principles for Institutions of Higher Education (https://www.cdc.gov/coronavirus/2019-ncov/community/collegesuniversities/considerations.html\#principles) recognize that universities and schools must work together to slow the spread of diseases and protect vulnerable students, staff, and faculty to help ensure a safe and healthy learning environment (Veenema, 2020). It is imperative for nurse educators to help nurses follow professional guidelines for managing COVID-19 in health care systems so that patients can receive the best care and have the best chance of survival. In some circumstances, the guidelines may seem unrealistic, far-fetched, or an overreaction. However, if guidelines are not followed, then the chances of increasing the spread of coronavirus and the prevalence of COVID-19 prevail. Nurses may choose to advocate for such things as compensation pay and adequate equipment and supplies to safely care for COVID-19 patients through advocacy organizations such as the American Nurses Association (ANA, 2020).

From a systems perspective, it is important for nurses to be at the table with the decision makers of professional organizations who are setting the standards of conduct (National League for Nursing, 2014; Stalter \& Arms, 2016). The Nurses on Boards Coalition (2018) was created to bring together nursing and national organizations to build healthier communities in the United States, ensuring that nurses' voices are heard at the decision-making level. For example, as care providers progress toward leadership in managing COVID-19 in health systems (message 7), they are encouraged to join professional associations such as the ANA, who continue to advocate for PPE for all health care providers, and also set the standards for nursing codes of professional conduct during unusual medical circumstances. The ANA (2020) has urged the CDC to address the following two issues:

(a) Investigate and communicate on the transmission mode for coronavirus so that decisions about appropriate PPE are based on the best information available.

(b) Identify metrics for when the interim guidance will be rescinded to ensure that clinical providers and health care facilities can prepare to continue caring for their patients and communities.

Although it is difficult to know whether health care providers are adhering to professional standards, it is advised that data be collected to determine this. This can be accomplished through observation research, surveys to health care providers and patients, and measuring the outcomes of patients in relation to the COVID-19 education their providers have received. It is the era for nurse educators to insist that academic systems secure research funding to support supercomputer technologies that can be used to analyze big data for predictive clinical models to yield health outcomes (WHO, 2020a). Nurse 
educators can also work to support academic-practice partnerships that foster workforce development opportunities, especially supporting overburdened health care workers (Phillips et al., 2019; Phillips et al., 2020).

\section{Message 6: Decision Making and Application of System-Level Awareness Using Utilitarian Ethics/Distributive Justice}

Message 6 addresses the macro-level perspective linked to ethics and moral distribution of resources in our country and focuses on decision making and the application of system-level awareness by use of utilitarian ethics and/or distributive justice. As nurses advance toward leadership in managing COVID-19 in health systems, they may encounter difficult choices in determining which patients will be prioritized to receive care due to the increases in the incidence of COVID-19 amid limited resources such as hospital beds or ventilators (Mounk, 2020). For example, individual health care providers on the front line may be faced with deciding whether some patients will receive treatment based on their age, potential for survival or prognosis, and productivity in society (Ives, 2020). This decision making, known as medical utilitarianism or distributive justice, was first described by Mill (1879). Since then, it has been embedded into community health textbooks, preserved for pandemic management. In response to COVID-19, utilitarianism has become a new reality for many among shortages of PPE, medical equipment, personnel, and hospital beds.

When utilitarian ethics is applied to the COVID-19 pandemic, health care providers may need to make prompt and difficult care-related decisions by consideration of maximizing the benefit for the greatest number of people, or the greater good of society, rather than simply treating patients on a first come, first served basis (Lubbe, 2020). Nurses must be involved in the distributive justice process, not only in helping to develop professional system-level decisions about allocation of resources and care, but also to be a resource for other nurses and professionals on ethical decision making, particularly advocating for dignified deaths. It is recommended that nurses stay abreast of CDC guidelines for ethical decision making while honoring the value of human life during pandemic/disaster circumstances. Hick et al. (2020) described the need for health care facilities to develop strategies using the best available clinical information for surge capacity plans while optimizing resources to obtain the most benefit from limited resources.

\section{Message 7. Professional Nurse Leadership in Complex Health Care Systems-Maintaining Confidence and Employing a Relationship-Based Philosophy}

Message 7 addresses human needs-based care through professional nurse leadership in complex health care systems. This involves demonstrating confidence and employing a relationship-based philosophy through compassion and empathy for oneself, patients, families, and peers. The pinnacle of this message is using systems thinking to lead the management of COVID-19 in health systems. Nurses at this level of systems thinking demonstrate high critical reasoning and an increased awareness of interdependencies with vital members of the health care team. Leadership within a health system inundated with COVID-19 patients can lend itself to the best possible patient outcomes by holding health care providers accountable through relationship-based care (RBC). RBC focuses on relationships between oneself, health care providers, and patients and their families (Koloroutis, 2004). Public health 
leaders add "the community" as a fourth relationship priority, referring to it as relationship-centered care (RCC) (Nundy \& Oswald, 2014).

Leaders advocating for RBC and RCC believe that the patient is not considered in isolation from all others, but considers the contributions from the family, health care team, health systems, and communities for patients' overall well-being. The health care team's capacity to develop a robust awareness of iniquitous violations flowing from internal and external systems helps to regulate behavior within highly reliable organizations (Chassin \& Loeb, 2013). When applied to management of COVID-19 in health care systems, iniquitous violations are defined as anything that is grossly unfair or morally wrong (Oxford Online Dictionary, 2020); specifically, it is any behavior that jeopardizes infection control, such as not having or properly using PPE, not providing quality care to anyone who desires it, or not supporting a patients' right to a dignified death.

From a systems thinking perspective, the collective mindfulness of RBC or RCC unites the patient, team, and organization as diligent effort, holding one another accountable for adhering to patient quality and safety measures that prevent the outspread of the coronavirus. The idea is to be gentle with oneself and others but aggressive with virus control. The resulting impact is systemwide health protection while defeating the ominous threat. Gentleness with self is key; RBC posits that self-care is the fundamental requirement for quality patient care and healthy interpersonal relationships. As frontline defenders of health, the public considers nurses and other health care professionals to be heroes with the greatest opportunity to influence change. In essence, if health care teams role model health behaviors, such as self-care and COVID-19 prevention, the public will follow (Institute of Medicine, 2001).

Nurses must engage in self-care for sustainability during times of societal need (Beach et al., 2006). Nurses are critically needed to care for the most vulnerable and must protect themselves from infection with coronavirus so they can be available to serve the public. Secondary traumatic stress (STS) can take an emotional toll on nurses and responders (CDC, 2020). According to the CDC (2020), self-care for health care professionals coping with managing COVID-19 include such things as:

acknowledging that STS can impact anyone helping families after a traumatic event

learning the symptoms including physical (fatigue, illness) and mental (fear, withdrawal, guilt)

allowing time for you and your family to recover from responding to the pandemic

creating a menu of personal self-care activities that you enjoy, such as spending time with friends and family (if possible), exercising, or reading a book

taking a break from media coverage of COVID-19

joining a support group

asking for help if you feel overwhelmed or concerned that COVID-19 is affecting your ability to care for your family and patients as you did before the outbreak

Other self-care suggestions from the WHO (2020) include eating a nutritious diet to maintain your immune system, limiting alcohol consumption, avoiding sugary drinks, not smoking, and exercise. 
Additional self-care suggestions include getting enough sleep, deep breathing, meditation, mental imagery or visualization, journal writing, and yoga, Tai chi, or Qigong (American Holistic Nurses Association, 2020).

Leaders must be empowered through system-based authority to implement, oversee, and evaluate policies for optimal care of vulnerable COVID-19 patients. The WHO (2020) guidelines set the standard for global awareness, as leaders can stay abreast and refer to them in leading and managing COVID-19. For example, WHO (2020) daily press briefings are available offering global updates and information to slow transmission of the virus to reduce the burden on health systems. In addition, simulation exercises and online training are available for professional and personal preparedness and response to COVID-19 (WHO, 2020a). Health system leaders need to be creative in working with the various components of the health system to care for those infected with COVID-19, such as using community centers to test, isolate, and/or care for infected patients (WHO, 2020a).

Support for collecting data on the spread and treatment is essential in preventing resurgences of COVID19 worldwide. For example, The Solidarity Trial is a WHO-led global study to investigate which treatment(s) are more effective in addressing the spread of COVID-19 (WHO, 2020b). Although this pandemic is presenting many challenges to health care providers worldwide to address the needs of many patients without effective treatments, this is an opportunity for nursing leadership to combat an enemy against humanity while paving the way for an improved future global health care system.

\section{Recommendations and Conclusion}

Nurses are courageous and indispensable during this horrific pandemic, as they have been throughout history under similar circumstances such as during the 1918 influenza outbreak ("Spanish Flu") (Clark et al., 2020). Nurses have been at the global forefront, knowing they themselves could contract the same illness while caring for infected patients. The SAM provides sound guidance in progressing toward leadership in managing and slowing the spread of COVID-19 worldwide. Nurse educators are wellpositioned to educate nurses about the use of the SAM during critical times when it can be the most useful. This is a unique time in history when nursing can shine in terms of "doing good" for the public by keeping abreast of current information amidst their own anxiety and fears, while progressing toward leadership in managing the COVID-19 pandemic in health systems. It is a disturbing time for all of humanity, but the pandemic provides nursing with an opportunity to improve our struggling health care systems worldwide through leadership in systems thinking, setting the stage for improved future patient outcomes as the world moves through the stages of "opening up" toward a new reality. 


\section{References}

Airth-Kindree N. M., Kirkhorn L. E. C. (2016). Ethical grand rounds: Teaching ethics at the point of care. Nursing Education Perspectives, 37(1), 48-50 PMID: 27164779

American Holistic Nurses Association. (2020, March). Holistic self-care for nurses. https://www.ahna.org/Membership/Member-Advantage/Whatisself-care

American Nurses Association. (2020, May). Response to COVID-19. https://www.nursingworld.org/news/news-releases/2020/ana-responds-to-coronavirus-pandemicdeclaration/

Barbera J. A., Macintyre A. G., Knebel A., Trabert E. (2007). Medical surge capacity and capability:Amanagement system for integrating medical and health resources during large-scale emergencies. U.S. Department of Health and Human Services. https://www.phe.gov/preparedness/planning/mscc/handbook/documents/mscc080626.pdf

Bassetti M., Vena D., Giacobbe D. R. (2020). The novel Chinese coronavirus(2019-nCoV) infections: Challenges for fighting the storm. European Journal of Clinical Investigation, e13209, 10.1111/eci.13209.

Battegay M., Kuehl R., Tschudin-Sutter S., Hirsch H. H., Widmer A. F., Neher R. A. (2020). 2019-novel Coronavirus(2019-nCoV): Estimating the case fatality rate:Aword of caution. Swiss Medical Weekly, 150(0506), w20203 10.4414/smw.2020.20203 PMID: 32031234

Beach M. C., Inui T. the Relationship-Centered Care Research Network. (2006). Relationship-centered care.Aconstructive reframing. Journal of General Internal Medicine, 21(1, Suppl. 1), S3-S8 10.1111/j.1525-1497.2006.00302.x PMID: 16405707

Catalano J. T. (1997). Ethical decision making in the critical care patient. Critical Care Nursing Clinics, 9(1), 45-52 10.1016/S0899-5885(18)30290-9 PMID: 9136344

Centers for Disease Control and Prevention. (2020, March). Coronavirus disease 2019. https://www.cdc.gov/

Channappanavar R., Perlman S. (2017, July). Pathogenic human coronavirus infections: Causes and consequences of cytokine storm and immunopathology. In Seminars in immunopathology(Vol. 39, No. 5, pp. 529-539). Springer Berlin Heidelberg. https://link.springer.com/article/10.1007/s00281-017-0629-x

Chassin M. R., Loeb J. M. (2013). High-reliability health care: Getting there from here. The Milbank Quarterly, 91(3), 459-490 10.1111/1468-0009.12023 PMID: 24028696

Clark J., Stroh E., D'Antonio P. (2020, May). Calm, cool, courageous: Nursing and the 1918 Influenza pandemic. https://www.nursing.upenn.edu/history/publications/calm-cool-courageous/

Dolansky M. A., Moore S. M. (2013). Quality and safety in nursing education. The key is systems thinking. Online Journal of Issues in Nursing, 18(3),1PMID: 26812094

Hick J. L., Hanfling D., Wynia M. K., Pavia A. T. (2020). Duty to plan: Health care, crisis standards of care, and novel coronavirus SARSCoV-2. National Academy of Medicine Perspectives. https://nam.edu/dutyto-plan-health-care-crisis-standards-of-care-and-novel-coronavirus-sars-cov-2/ 
Institute of Medicine, Committee on Health, Practice, \& Policy. (2001). Health and behavior: The interplay of biological, behavioral, and societal influences. National Academies Press.

Ives J. (2020, May). Coronavirus may force UK doctors to decide who they'll save. The Guardian. https://www.theguardian.com/commentisfree/2020/mar/14/coronavirus-outbreak-older-peopledoctors-treatment-ethics

Koloroutis M.(Ed.). (2004). Relationship-based care:Amodel for transforming practice. Creative Health Care Management, Inc.

Lubbe W. (2020, March). Corona triage:Acommentary on the triage recommendations by Italian SIAARTI medicals regarding the corona crisis. Verfassungsblog. https://verfassungsblog.de/corona-triage-2/

Makary M. A., Daniel M. (2016). Medical error-the third leading cause of death in the US. British Medical Journal, 353, i2139 10.1136/bmj.i2139 PMID: 27143499

Marcus L. J., Dorn B. C., Ashkenazi I., Henderson J., McNulty E. J. (2015). Meta-leadership:Aframework for building leadership effectiveness. http://npli.sph.harvard.edu

McLean M. (2012). Ethical preparedness for pandemic influenza:Atool-kit. Markkula Center for Applied Ethics at Santa Clara University. https://www.scu.edu/ethics/focus-areas/bioethics/resources/ethicalpreparedness-for-pandemic-influenza/

Mill J. S. (1879). Utilitarianism(7th ed.). Long, Green \& Co.

https://books.google.com/books?id=hm4IAQAAIAAJ\&pg=PP11\&source=kp_read_button\&ppis=_c\#v=on epage \&q\&f=false

Mounk Y. (2020, March). The extraordinary decisions facing Italian doctors. The Atlantic. https://www.theatlantic.com/ideas/archive/2020/03/who-gets-hospital-bed/607807/

National League for Nursing. (2014). National League for Nursing joins national coalition launched to place 10,000 nurses on health-related boards by 2020. http://www.nln.org/newsroom/newsreleases/news-release/2014/11/18/national-league-for-nursing-joins-national-coalition-launched-toplace-10-000-nurses-on-health-related-boards-by-2020

Notarnicola I., Stievano A., Pulimeno A., Rocco G. (2019, June). Systems thinking, complex adaptive systems and health: An overview on new perspectives for nursing education. In DiMascio T.(Eds.), International Conference in Methodologies and intelligent Systems for technology enhanced learning, 8th International conference(pp. 285-292). Springer, Cham. 10.1007/978-3-319-98872-6_34

Nundy S., Oswald J. (2014). Relationship-centered care:Anew paradigm for population health management. Health Care, 2, 216-219 10.1016/j.hjdsi.2014.09.003 PMID: 26250627

Nurses on Boards Coalition. (2018). Nurses on Boards Coalition: Strategic imperatives. https://www.nursesonboardscoalition.org/about/

Oxford Online Dictionary. (2020). Iniquitous. In Oxford Online Dictionary. https://www.oxfordlearnersdictionaries.com/us/definition/english/iniquitous 
Phillips J. M., Phillips C.R., Kauffman K. R., Gainey M., Schnur P. L. (2019). Academic-practice partnerships:Awin-win. The Journal of Continuing Education in Nursing, 50(6), 282-288.

10.3928/00220124-20190516-09

Phillips J. M., Stalter A. M., Barba M., Bonnett P. L., Brodhead J., Wiggs C. (2020). Systems thinking to improve patient outcomes through RN to BSN improvement projects in academic-practice partnerships. International Quality and Safety Education for Nurses(Abstract accepted, conference postponed).

Phillips J. M., Stalter A. M., Dolansky M. A., McKee-Lopez G. (2016). Fostering future leadership in quality and safety in health care through systems thinking. Journal of Professional Nursing, 32(1) 15-24. 10/1016/jprofnuurs.2015.06.003

Phillips J. M., Stalter A. M., Winegardner S., Wiggs C.M., Jauch A. (2018). Systems thinking and incivility in nursing practice: An integrative review. Nursing Forum, 53(3), 286-298 10.1111/nuf12250

Quality and Safety Education for Nurses. (2020). QSEN competencies. https://qsen.org/competencies/pre-licensure-ksas/

Rothan H. A., Byrareddy S. N. (2020). The epidemiology and pathogenesis of coronavirus disease(COVID19) outbreak. Journal of Autoimmunity, 109, 102433 10.1016/j.jaut.2020.102433 PMID: 32113704

Smith D., Machin M. A., Beccaria G. (2017). The organisational socio-ecological(in) civility model: Framing multilevel(in) civility effects on employees within organisational climate and culture. https://eprints.usq.edu.au/33030/

Stalter A. M., Arms D. (2016) Serving on organizational boards: What nurses need to know. OJIN: The Online Journal of Issues in Nursing. 21(2). 10.3912/OJIN.Vol21No02PPT01 http://www.nursingworld.org/MainMenuCategories/ANAMarketplace/ANAPeriodicals/OJIN/TableofContents/Vol-21-2016/No2-May-2016/Articles-Previous-Topics/Serving-onOrganizational-Boards.html

Stalter A. M., Jauch A. (2019). Systems thinking education in RNBSN programs:Aregional study. Nursing Education, 44(2), 112-115 doi 10.1097/NNE.0000000000000558

Stalter A. M., Phillips J. M., Ruggiero J. S., Scardaville D. L., Merriam D., Dolansky M. A., Goldschmidt K. A., Wiggs C. M., Winegardner S. (2016). Concept analysis of systems thinking. Nursing Forum, 52(4), 323-330. doi: https://doi-org.proxy.ulib.uits.iu.edu/10.1111/nuf.12196

Stalter A. M., Phillips J. M., Ruggiero J. S., Wiggs C. M., Brodhead J., Swanson K. (2019). Systems perspective for incivility in academia: an integrative review. Nursing education perspectives, 40(3), 144150.

Stanford Medicine. (2020). Remdesivir tested at Stanford Medicine, authorized for emergency use against COVID-19. http://med.stanford.edu/news/all-news/2020/05/remdesivir-gets-emergencyapproval-from-fda-for-covid-19.html

U.N. News. (2020, May). UN health chief announces global "solidarity trial" to jumpstart search for COVID-19 treatment. https://news.un.org/en/story/2020/03/1059722

Veenema T. G. (2020). Disaster nursing and emergency preparedness(4th ed.). Springer. 
WebMD. (2020). Coronavirus(COVID-19) vaccine. https://www.webmd.com/lung/covid-19-vaccine\#1

Whitehouse.gov. (2020, May). Coronavirus: Resources, updates, and what you should know.

https://www.whitehouse.gov/

World Health Organization. (2020a). Coronavirus. https://www.who.int/health-

topics/coronavirus\#tab=tab_1

World Health Organization. (2020b). The "solidarity" clinical trial for COVID-19 treatments.

https://www.who.int/emergencies/diseases/novel-coronavirus-2019/global-research-on-novelcoronavirus-2019-ncov/solidarity-clinical-trial-for-covid-19-treatments

Zarracina J., Rodriguez A. (2020, May). What does the coronavirus do to your body? Everything to know about the infection process. USA Today. https://www.usatoday.com/in-depth/news/2020/03/13/whatcoronavirus-does-body-covid-19-infection-process-symptoms/5009057002/

Zou L. (2020). SARS-CoV-2 viral load in upper respiratory specimens of infected patients. The New

England Journal of Medicine. https://www.nejm.org/doi/pdf/10.1056/NEJMc2001737?articleTools=true 
Table 1 Systems Awareness Model (SAM) Steps Modified to Manage COVID-19 in Health Systems

\begin{tabular}{|c|c|c|c|}
\hline Step & SAM & $\begin{array}{l}\text { Modified SAM to Manage COVID-19 in Health Care } \\
\text { Systems }\end{array}$ & $\begin{array}{l}\text { Key Messages for Nurse } \\
\text { Educators and Nurses }\end{array}$ \\
\hline 1 & $\begin{array}{l}\text { Basic nursing } \\
\text { care }\end{array}$ & $\begin{array}{l}\text { Basic nursing knowledge and care of COVID-19 } \\
\text { patients }\end{array}$ & $\begin{array}{l}\text { Know as much as possible } \\
\text { about the coronavirus and } \\
\text { nursing management of it in } \\
\text { health systems }\end{array}$ \\
\hline 2 & $\begin{array}{l}\text { Systems-based } \\
\text { care }\end{array}$ & $\begin{array}{l}\text { System based awareness of managing infected } \\
\text { patients }\end{array}$ & $\begin{array}{l}\text { Be aware of Isolation } \\
\text { procedures across the health } \\
\text { care system (i.e., policies for } \\
\text { all professions, students, and } \\
\text { visitors), including the local, } \\
\text { regional, and national } \\
\text { resources. }\end{array}$ \\
\hline 3 & $\begin{array}{l}\text { Critical } \\
\text { reasoning about } \\
\text { challenges in } \\
\text { health care }\end{array}$ & $\begin{array}{l}\text { Critical reasoning about today's health care } \\
\text { challenges: Weighing the risks between caring for } \\
\text { patients and becoming infected }\end{array}$ & $\begin{array}{l}\text { Weigh risk under crisis care } \\
\text { standards that do not } \\
\text { supersede the provision of } \\
\text { safe, quality care }\end{array}$ \\
\hline 4 & $\begin{array}{l}\text { QSEN mastery in } \\
\text { systems level } \\
\text { synthesis }\end{array}$ & $\begin{array}{l}\text { QSEN Competency Mastery within overwhelmed } \\
\text { health systems } \\
\text { QSEN Competencies include patient centered care, } \\
\text { teamwork and collaboration, evidence-based } \\
\text { practice, quality improvement, safety and } \\
\text { informatics }\end{array}$ & $\begin{array}{l}\text { Assess whether QSEN } \\
\text { competencies are adhered } \\
\text { to across the health care } \\
\text { system and collaborate with } \\
\text { interprofessional teamsto } \\
\text { provide safe, quality, } \\
\text { patient-centered care using } \\
\text { the best available evidence } \\
\text { and technology }\end{array}$ \\
\hline 5 & $\begin{array}{l}\text { System level } \\
\text { analysis based } \\
\text { on professional } \\
\text { standards of } \\
\text { conduct }\end{array}$ & $\begin{array}{l}\text { System level analysis based on professional } \\
\text { standards of conduct: WHO, CDC, State, Joint } \\
\text { Commission, Universities and Schools of Nursing }\end{array}$ & $\begin{array}{l}\text { Determine whether } \\
\text { professional standards being } \\
\text { adhered to across academic- } \\
\text { practice systems to decrease } \\
\text { the spread of infection }\end{array}$ \\
\hline 6 & $\begin{array}{l}\text { Decision making } \\
\text { and application } \\
\text { of system level } \\
\text { awareness }\end{array}$ & $\begin{array}{l}\text { Decision making and application of system level } \\
\text { awareness using utilitarian ethics/distributive justice }\end{array}$ & $\begin{array}{l}\text { Become involved in } \\
\text { decisions about utilitarian } \\
\text { ethics/distributive justice }\end{array}$ \\
\hline 7 & $\begin{array}{l}\text { Professional } \\
\text { nurse leadership } \\
\text { in complex } \\
\text { health care } \\
\text { systems }\end{array}$ & $\begin{array}{l}\text { Professional nurse leadership in complex health care } \\
\text { system: Maintaining confidence and employing a } \\
\text { relationship-based philosophy }\end{array}$ & $\begin{array}{l}\text { Lead health systems by } \\
\text { uniting the patient, team, } \\
\text { and organization through } \\
\text { diligent effort, holding one } \\
\text { another accountable for } \\
\text { adhering to quality and } \\
\text { safety measures that } \\
\text { prevent the outspread of the } \\
\text { coronavirus } \\
\text { Nurses set an example } \\
\text { through self-care to prevent } \\
\text { spread of infection }\end{array}$ \\
\hline
\end{tabular}




\section{Author Affiliation}

Dr. Phillips is Clinical Professor, Director, RN to BSN Online Degree Completion Option, Indiana University, Indianapolis, Indiana; and Dr. Stalter is Professor, Wright State University, College of Nursing and Health, Dayton, Ohio.

The authors have disclosed no potential conflicts of interest, financial or otherwise. 